\title{
Determinação da Orientação Estratégica do Polo Moveleiro do Alto Vale do Rio Negro
}

\author{
Ailson Augusto Loper ${ }^{1}$, Alexandre Nascimento de Almeida ${ }^{2}$, \\ João Carlos Garzel Leodoro da Silva ${ }^{1}$, Humberto Angelo ${ }^{3}$ \\ ${ }^{1}$ Departamento de Economia Rural, Universidade Federal do Paraná - UFPR, Curitiba/PR, Brasil \\ ${ }^{2}$ Faculdade UnB Planaltina - FUP, Universidade de Brasília - UnB, Brasília/DF, Brasil \\ ${ }^{3}$ Departamento de Engenharia Florestal, Universidade de Brasilia - UnB, Brasilia/DF, Brasil
}

\begin{abstract}
RESUMO
O objetivo do trabalho é caracterizar e identificar a estratégia competitiva desenvolvida pelo polo moveleiro do Alto Vale do Rio Negro a partir das três estratégias genéricas propostas por Porter (1980): baixo custo, diferenciação e foco. A identificação das estratégias foi por meio da aplicação de questionário e análise de correspondência. Em geral, as empresas do polo são exportadoras, de médio ou pequeno porte, produzem móveis residenciais, retilíneos sob encomenda ou de forma seriada. A análise dos dados evidenciou que o grupo de moveleiras analisadas não apresenta uma estratégia genérica pura, pois as estratégias de baixo custo e diferenciação foram consideradas igualmente importantes. Verificou-se que as firmas com maior parte da sua produção voltada para o mercado externo adotam a estratégia de baixo custo e as moveleiras de grande porte perseguem a estratégia de baixo custo e diferenciação simultaneamente.
\end{abstract}

Palavras-chave: indústria de móveis, concorrência, planejamento empresarial.

\section{Determination of Strategic Orientation of the Alto Vale do Rio Negro Furniture Pole}

\begin{abstract}
The objective is to identify and characterize the competitive strategy developed by the furniture production center of the Alto Vale do Rio Negro from the three generic strategies proposed by Porter (1980): low cost, differentiation and focus. The identification of strategies was through a questionnaire and correspondence analysis. In general, companies are exporters, medium-sized or small, producing residential furniture, custom straight or serially. Data analysis showed that the group of companies analyzed does not have a generic pure strategy because the differentiation and low cost strategies were considered equally important. It was found that the companies with most of their production for foreign markets adopting a low cost strategy and large companies pursuing a strategy of differentiation and low cost simultaneously.
\end{abstract}

Keywords: furniture industry and trade, competition, corporate planning. 


\section{INTRODUÇÃO}

Segundo o Instituto Brasileiro de Geografia e Estatística - IBGE (2014), a indústria brasileira de móveis é formada por quase 10 mil micro, pequenas e médias empresas que geram em torno de $265 \mathrm{mil}$ empregos, na grande maioria de capital nacional. Essas empresas localizam-se na região centro-sul do país, constituindo em alguns Estados, polos moveleiros, a exemplo de Bento Gonçalves, no Rio Grande do Sul; São Bento do Sul (atualmente denominado Alto Vale do Rio Negro), em Santa Catarina; Arapongas no Paraná; Mirassol, Votuporanga e São Paulo, em São Paulo; Ubá em Minas Gerais e Linhares no Espírito Santo, cada um deles com estruturas produtivas e linhas de produtos diferenciadas.

A indústria de móveis de madeira do Brasil exportou em 2013 o montante de 437 milhões de dólares. A região Sul do Brasil responde por mais de $90 \%$ do valor exportado de móveis de madeira do Brasil e, acrescentando o estado de São Paulo, esse valor sobe para 99\% das exportações nacionais. Em 2013, os principais estados exportadores de móveis de madeira foram: Rio Grande do Sul (37,8\%), Santa Catarina (36,3\%), Paraná (16,6\%) e São Paulo (7,9\%) (AliceWeb, 2014).

Durante a década de 1990, a cadeia produtiva de madeira e móveis em termos mundiais sofreu grandes transformações com consequentes ganhos de produtividade, não somente no que se refere à introdução de equipamentos automatizados na área produtiva e à utilização de novas técnicas de gestão, como também ao uso de outras fontes de matérias-primas (UNICAMP, 2002).

Conforme relatório do Banco Regional de Desenvolvimento do Extremo Sul - BRDE (2006) ocorreu na indústria de móveis a tecnificação dos processos produtivos e a deslocalização diante das transformações da indústria mundial, que podem ser sintetizadas em: avanços tecnológicos; descentralização da produção; especialização dos produtores de componentes; redução de custos; aumento da eficiência na cadeia produtiva; introdução de novas matérias-primas como as chapas de MDF.

Segundo Gorini (2000), estas transformações influenciaram o mercado consumidor, especialmente no segmento de móveis lineares retilíneos (fabricados a partir de painéis de madeira), sendo que neste segmento, em países desenvolvidos, o ciclo de reposição sofreu grande redução, aumentando o dinamismo da indústria.

A necessidade de maximização dos ganhos e minimização dos custos tem direcionado a indústria moveleira mundial para um caminho de transformações no processo produtivo, ou seja, uma forte mudança no perfil da organização industrial (Coelho, 2003).

Essa situação, sem dúvida, gera mudanças no comportamento da indústria moveleira brasileira que necessita atingir níveis maiores de competitividade, superando os problemas conjunturais da economia no País e também estruturais do setor.

Neste contexto, torna-se fundamental aos empresários da indústria moveleira desenvolver suas estratégias, estando preparados para enfrentarem um ambiente de negócios cada vez mais competitivo. Evidencia-se, portanto a necessidade de geração de informações relativa às estratégias competitivas praticadas pelas empresas.

Nesse intuito, o objetivo do trabalho consiste em analisar as estratégias competitivas desenvolvidas pelas fábricas que abrangem o Polo Moveleiro do Alto Vale do Rio Negro (PMAVRN) conforme o porte e vocação exportadora das empresas.

\section{METODOLOGIA}

\section{1. Área de estudo}

A área abrangida por este estudo está localizada no norte do Estado de Santa Catarina, distante $249 \mathrm{~km}$ da capital do estado, Florianópolis (Figura 1).

O PMAVRN inclui os municípios de São Bento do Sul, Campo Alegre e Rio Negrinho, totalizando 130 mil pessoas nas três regiões em 2011. Este polo gera oportunidade de trabalho para cerca de $20 \mathrm{mil}$ pessoas (IBGE, 2014).

O fator determinante para a escolha desta região foi à importância do polo em termos de exportação de móveis, bem como a importância deste segmento na geração de empregos na região. Segundo Denk (2006), esse é o maior polo exportador de móveis do Brasil, exportando cerca de $80 \%$ do que produz. Em 2013 giraram em torno de US\$ 115 milhões, 


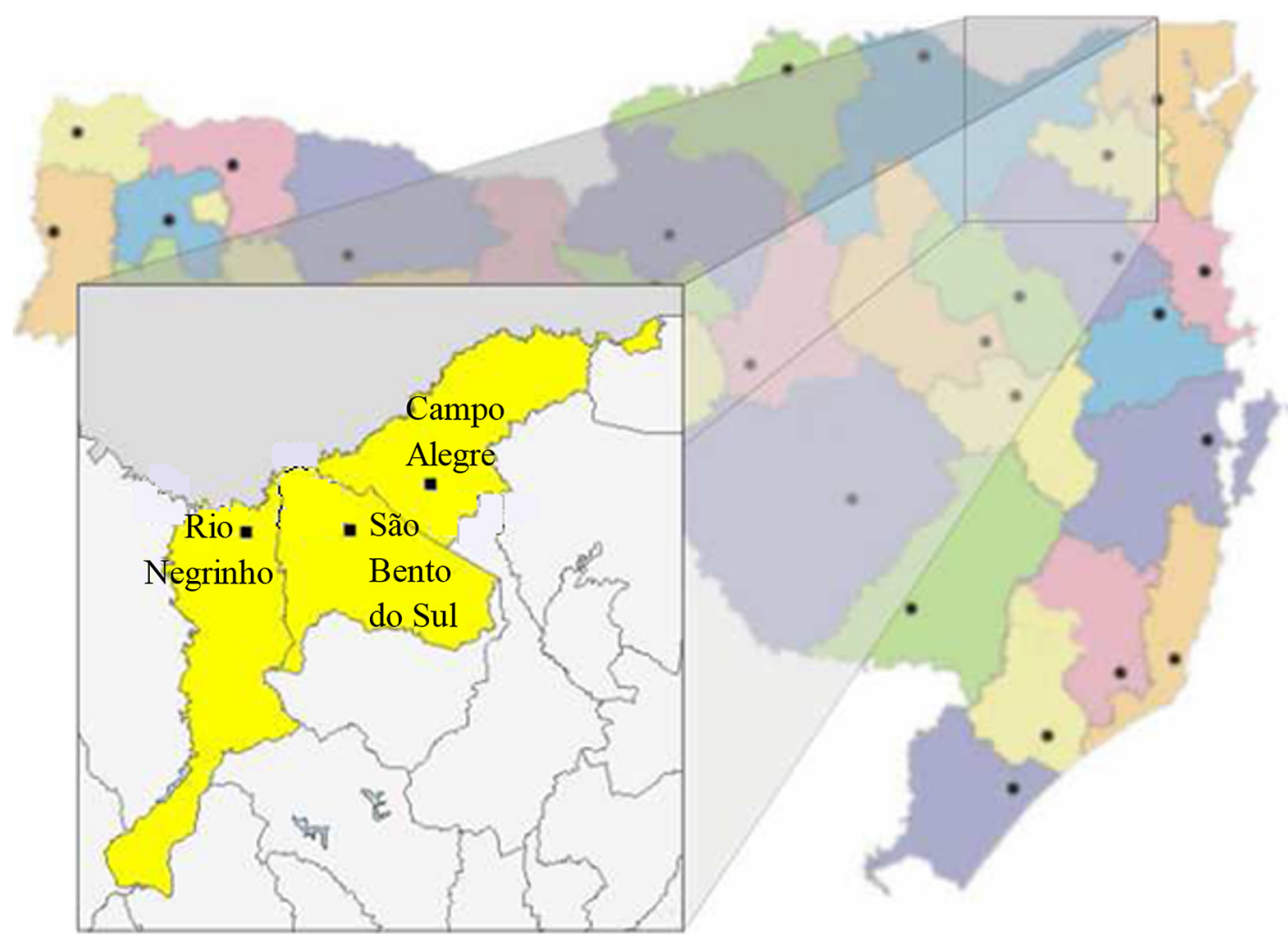

Figura 1. Polo moveleiro do Alto Vale do Rio Negro.

Figure 1. Furniture center of the Alto Vale do Rio Negro.

representando cerca de $70 \%$ das exportações de móveis de Santa Catarina e 26\% das exportações brasileiras (AliceWeb, 2014).

\subsection{Referencial teórico}

A concorrência em uma indústria apresenta raízes em sua estrutura econômica básica e segundo Porter (1980), depende de cinco forças competitivas básicas que são apresentadas na Figura 2.

O conjunto destas forças competitivas básicas determina o potencial de lucro final, o desempenho da empresa na indústria.

Para enfrentar essas forças que regem o mercado, a concorrência, Porter (1980) apresenta três abordagens estratégicas genéricas: Diferenciação, Baixo Custo e Foco. Conforme o autor, as estratégias genéricas são potencialmente bem-sucedidas para superar as outras empresas em uma indústria (Figura 3).

O conceito de estratégias genéricas advém do fato de que alguns autores (Milles et al., 1978; Porter, 1980;
Hambrick, 1983a; Mintzberg, 1988) acreditam ser possível definir uma tipologia de estratégias suficientemente amplas de tal forma que elas sejam aplicáveis a qualquer empresa e em qualquer tipo de indústria. Ou, dito de outra forma, poderia ser identificado um número limitado de arquétipos estratégicos que capturariam a essência das diversas posturas competitivas da maioria das empresas (Hambrick, 1983b).

Segundo Porter (1980), as empresas que apresentariam melhor desempenho seriam aquelas que conseguissem aplicar uma, e apenas uma, das três estratégias genéricas. As empresas que procurassem uma posição híbrida foram por ele designadas como stuck-in-the-middle (meio-termo).

Este posicionamento tem lhe valido diversas críticas (Murray, 1988; Miller \& Dess, 1993); o próprio Porter (1991) chegou a mencionar, em poucas ocasiões e muito superficialmente, que seria viável a perseguição simultânea das estratégias de baixo custo e de diferenciação, dada uma determinada conjugação muito específica de circunstâncias. 


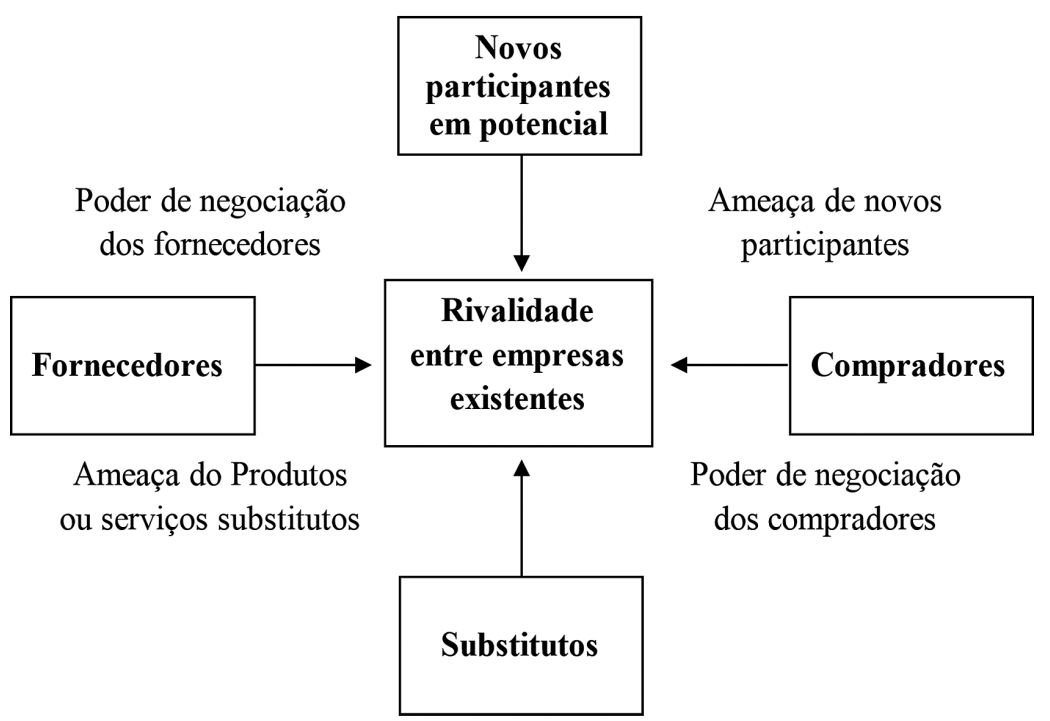

Figura 2. Forças que dirigem a concorrência na indústria.

Figure 2. Forces driving industry competition. Fonte: Porter (1980).

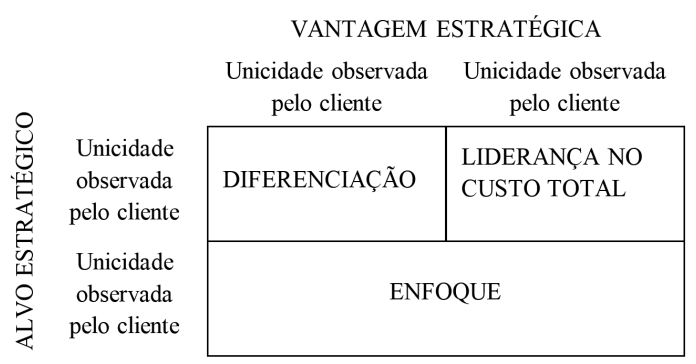

Figura 3. Estratégias genéricas de Porter.

Figure 3. Porter generic strategies. Fonte: Porter (1980).

\subsection{Referencial analítico}

\subsubsection{Tamanho da amostra}

Devido aos dados coletados serem em escala de medida não métrica, a determinação do tamanho da amostra foi com base na estimativa da proporção populacional para população finita, já que o tamanho da amostra (24 empresas) é superior a 5\% do tamanho da população (73 empresas). Para tanto, o julgamento da amostra foi conforme a Equação 1.

$n=\frac{N p q\left(Z_{\alpha / 2}\right)^{2}}{p q\left(Z_{\alpha / 2}\right)^{2}+(N-1) E^{2}}$

Onde:

$\mathrm{n}=$ Número de indivíduos na amostra

$N=$ Tamanho da população

$\mathrm{Z}_{\alpha / 2}=$ Valor crítico que corresponde ao grau de confiança desejado $p^{\wedge}=$ Proporção populacional de indivíduos que pertence à categoria de interesse

$q^{\wedge}=$ Proporção populacional de indivíduos que não pertence à categoria de interesse $(\mathrm{q}=1-\mathrm{p})$

$E=$ Margem de erro

Conforme Levine et al. (2000) considerou-se os valores desconhecidos de $p^{\wedge} e q^{\wedge}$ como 0,5 e, similar a Weyne (2004), a margem de erro admitida foi de $20 \%$.

\subsubsection{Instrumental estatístico}

O instrumental estatístico utilizado para identificar a estratégia do PMAVRN é a análise de correspondência, apresentada nos mapas perceptuais e dendrogramas de cluster (Hair et al., 2005).

A vantagem dos mapas perceptuais além de ser uma técnica interessante para a visualização dos fenômenos é a sua grande flexibilidade em termos de premissas estatísticas. A única exigência estrita é a existência de uma matriz de dados contendo valores não negativos. Uma das desvantagens é que o método não serve para se testar hipótese, sendo necessária à utilização de outras técnicas quando esse for o objetivo (Hoffman \& Franke, 1986).

A vantagem da análise de cluster está em facilitar a interpretação do mapa de percepções, que pode se tornar muito complexo à medida que se tenham muitas variáveis (Martins, 2003). 


\subsubsection{Delineamento da análise}

Para um refinamento dos resultados e, consequentemente, um melhor entendimento da orientação estratégica do polo moveleiro, as análises foram realizadas com os dados agregados e desagregados. Os critérios adotados para a desagregação dos dados foram o porte da empresa e orientação da produção entre o mercado interno e externo.

Quanto ao porte, as empresas foram classificadas em microempresas (até 19 empregados), pequenas (20 a 99 empregados), médias (100 a 499 empregados) e grandes empresas (mais de 500 empregados). Sequencialmente as empresas foram desagregadas quanto ao mercado que destina a maior parte da sua produção, (doméstico ou exportação). A fim de facilitar a apresentação dos resultados foram adotadas as siglas correspondentes do Quadro 1.

\subsection{Banco de dados}

Os dados desta pesquisa foram obtidos por meio da aplicação pessoal de questionários com perguntas em escala de Likert direcionados a administração das empresas moveleiras do Alto Vale do Rio Negro. A escala de Likert mensura o grau de concordância dos entrevistados em relação a afirmações presentes no questionário, possibilitando respostas entre os seguintes atributos: discorda completamente, discorda, indiferente, concorda e concorda completamente.

Similar a Dess \& Davis (1984) e Vasques (2006), as perguntas foram associadas as três estratégias genéricas de Porter (1980) (Quadro 2).

\section{RESULTADOS E DISCUSSÕES}

\subsection{Amostragem}

Em relação à posição hierárquica dos respondentes a participação contou com presidentes, proprietários ou sócios (25\%), diretores (41\%), gerentes (25\%), o que totalizou $91 \%$, confirmando que as respostas estão alinhadas pelo grupo de decisão e gestão das empresas, representando o contexto estratégico.

A amostragem contou com 24 casos, ou seja, cerca de $33 \%$ da população de 73 empresas. Considerando a margem de erro de $20 \%$ sugerida por Weyne (2004), o tamanho mínimo da amostra requerida seria de 21 empresas, portanto, o erro amostral do estudo encontra-se em uma margem ligeiramente inferior a $20 \%$.

Além da amostra possuir um alinhamento condizente com o grupo de decisão das empresas, o seu tamanho foi representativo da população, permitindo afirmar que a amostra utilizada representa o pensamento estratégico do PMAVRN.

Quadro 1. Siglas adotadas para apresentação dos resultados.

Chart 1. Abbreviations adopted for presentation of results.

\begin{tabular}{|c|c|c|c|}
\hline \multicolumn{2}{|c|}{ Siglas para os atributos de importância } & M_D & Estratégia de Diferenciação para Média Empresa \\
\hline EI & Extremamente Importante & M_BC & Estratégia de Baixo Custo para Média Empresa \\
\hline MI & Moderadamente Importante & M_F & Estratégia de Foco para Média Empresa \\
\hline I & Importante & P_D & Estratégia de Diferenciação para Pequena Empresa \\
\hline PI & Pouco Importante & P_BC & Estratégia de Baixo Custo para Pequena Empresa \\
\hline NI & Nenhuma Importância & P_F & Estratégia de Foco para Pequena Empresa \\
\hline & Siglas para dados agregados & \multirow{2}{*}{\multicolumn{2}{|c|}{ Siglas para dados desagregados por destino da produção }} \\
\hline $\mathrm{BC}$ & Estratégia de Baixo Custo & & \\
\hline $\mathrm{F}$ & Estratégia de Foco & ME_D & $\begin{array}{l}\text { Estratégia de Diferenciação para empresas voltadas às } \\
\text { exportações }\end{array}$ \\
\hline $\mathrm{D}$ & Estratégia de Diferenciação & ME_BC & $\begin{array}{l}\text { Estratégia de Baixo Custo para empresas voltadas às } \\
\text { exportações }\end{array}$ \\
\hline \multicolumn{2}{|c|}{$\begin{array}{c}\text { Siglas para dados desagregados por porte da } \\
\text { empresa }\end{array}$} & ME_F & $\begin{array}{l}\text { Estratégia de Foco para empresas voltadas às expor- } \\
\text { tações }\end{array}$ \\
\hline G_D & $\begin{array}{l}\text { Estratégia de Diferenciação para } \\
\text { Grandes Empresas }\end{array}$ & MI_D & $\begin{array}{l}\text { Estratégia de Diferenciação para empresas voltadas ao } \\
\text { mercado interno }\end{array}$ \\
\hline G_BC & $\begin{array}{l}\text { Estratégia de Baixo Custo para } \\
\text { Grandes Empresas }\end{array}$ & MI_BC & $\begin{array}{l}\text { Estratégia de Baixo Custo para empresas voltadas ao } \\
\text { mercado interno }\end{array}$ \\
\hline G_F & $\begin{array}{l}\text { Estratégia de Foco para Grandes } \\
\text { Empresas }\end{array}$ & MI_F & $\begin{array}{l}\text { Estratégia de Foco para empresas voltadas ao mercado } \\
\text { interno }\end{array}$ \\
\hline
\end{tabular}


Quadro 2. Vinculações das variáveis consideradas com as estratégias de Porter.

Chart 2. Bindings of the variables considered with the Porter strategies.

\begin{tabular}{|c|c|c|}
\hline $\mathbf{n}^{\mathbf{0}}$ & Variável & Estratégia Genérica \\
\hline 2 & Desenvolvimento de novos produtos & \\
3 & Serviços complementares aos clientes & \\
4 & Controle de qualidade do produto & Diferenciação \\
\hline 5 & Pessoal treinado e experiente & \\
6 & Desenvolvimento de marca forte & \\
\hline 7 & Uso de novas técnicas ou métodos de marketing & Baixo Custo \\
\hline 8 & Propaganda e promoções & \\
\hline 9 & Entrega rápida ao cliente & \\
\hline 10 & Reputação/nome/marca no setor & \\
\hline 11 & Operação eficiente na produção de bens & \\
12 & Preço competitivo & \\
\hline 13 & Busca de suprimentos matéria-prima & Foco \\
\hline 14 & Florestas ou operações de colheita próprias & \\
\hline 15 & Investimentos em novos processos e equipamentos & \\
\hline 17 & Controle dos canais de distribuição & \\
\hline 19 & Atendimento a mercados regionais específicos & \\
\hline
\end{tabular}

\subsection{Identificação da orientação estratégica do polo}

\subsubsection{Estratégia global das empresas do polo}

A Figura 4 apresenta os resultados agregados indicando o grau de importância de cada estratégia genérica de Porter (1980).

As três estratégias genéricas de Porter (1980) são consideradas com diferentes níveis de importância pelas empresas do PMAVRN. Enquanto a tática de baixo custo foi declarada como de extrema importância, a de diferenciação teve um atributo de muita importância.

Já, a estratégia de foco, devido a sua proximidade com os atributos Importante, Nenhuma Importância e Pouco Importante, não permite uma análise conclusiva pelo mapa perceptual, em que a estratégia aparenta estar mais próxima do nível definido como importante. Esta dúvida somente é dirimida pelo uso do dendograma de cluster que a indica com maior proximidade do grau de pouca importância.

Porém, mais do que concluir que os empresários consideram a estratégia de foco como de pouca importância, deve-se inferir que, dado a uma proximidade muito semelhante de três níveis de importância, o
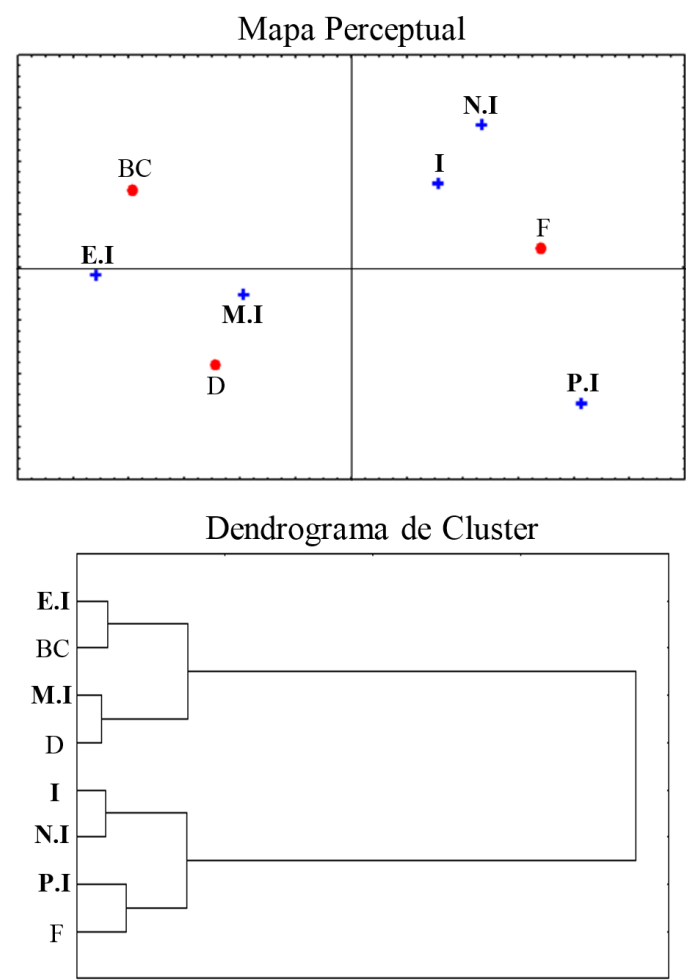

Figura 4. Indicativo da estratégia por meios do mapa perceptual e dendrograma de cluster.

Figure 4. Indicative of the strategy through the perceptual map and cluster dendrogram. 
que ocorre é a não apresentação de consistência no uso dos instrumentos estratégicos que a compõem a estratégia de foco.

Como o mapa perceptual e o dendrograma de cluster indicaram que as estratégias de baixo custo e diferenciação são consideradas de extremamente a muito importante, pode-se inferir que existe uma orientação estratégica híbrida (stuck-in-the-middle), podendo visualizar uma tendência mais forte à tática de baixo custo pela maior parte do grupo de empresas.

A opção pela estratégia híbrida com um foco maior em baixo custo aparenta ser um erro visto que alguns dos pressupostos para atuar em baixo custo é redução dos mesmos via aumento de escala e padronização, o que possibilita o aumento da escala.

Ocorre que as empresas deste polo têm uma marcante característica exportadora (Loper, 2007) e é composto basicamente por empresas de médio e pequeno porte (92\% do total), não possuindo escala de produção.

A estratégia de baixo custo de acordo com Porter (1980) exige a construção agressiva de instalações em escala eficiente, uma perseguição vigorosa de reduções em custo pela experiência, controle rígido do custo e das despesas gerais. Apenas com grandes investimentos é possível posicionar-se com sucesso utilizando a liderança em custo, o que cria uma barreira de entrada, dificultando a competição via preço para as pequenas empresas.

Este fato é facilmente comprovado, visto que em entrevistas realizadas em 2007 foram constatadas reclamações recorrentes em relação ao câmbio e a entrada da China em mercados que antes eram dominados por estas empresas com preços menores (obviamente não se está considerando o atual momento da crise econômica mundial) (Loper, 2007).

Ao mesmo tempo a importância demonstrada para estratégia de diferenciação, permite inferir a tentativa de uso de táticas para diferenciar os produtos de concorrentes. Porém não se pode considerar necessariamente que esta diferenciação ocorre pelo tipo de móvel produzido (retilíneos), em que 525 das empresas produzem somente este tipo de produto enquanto outras $38 \%$ das empresas fazem um mix com móveis torneados.

Poderia ser considerada a utilização desta estratégia, em parte pelas características de produzirem grande parte sob forma de encomenda, sendo que 39\% das empresas trabalham somente sob este conceito e mais $22 \%$ realizam um mix entre produção sob encomenda e seriados. Estas últimas, claramente não possuem um foco definido.

A falta de estratégia (stuck-in-the-middle) do polo é percebida tanto pelo setor como pelo Estado, resultando em várias iniciativas para criar a marca brasileira de móveis, assim, tentando diferenciar a produção. Porém não parece ter tido sucesso no conjunto do setor, e por consequência do polo, devendo ser questionado se é este o modelo que deve ser seguido, ou é necessário procurar ouros fatores de diferenciação que sejam mais efetivos.

Porém, visto que a opção inicial foi fundamentalmente baixo custo, é plausível considerar que os móveis do polo sejam reconhecidos nos mercados externos sob esta ótica, e a mudança de percepção dos clientes pode ser de difícil operacionalização.

Assim, outra opção também complexa seria o investimento em grandes unidades fabris, ou união das empresas do polo para continuar na estratégia de liderança em custo. Porém com grande competição da China e com as reduções de competitividade existente do "Custo Brasil" que vem sendo discutido há tempos como citado por Silva (1996).

\subsubsection{Estratégia por porte das empresas}

Visto existir a característica de estratégia híbrida no conjunto do polo, é importante saber se esta se repete por tamanho das empresas (Figura 5).

Nesta divisão também é possível distinguir três grupos: o primeiro em que as variáveis são percebidas como de extrema importância, no segundo considerado como muito importante e o último não demonstra uma clara definição de importância entre as variáveis.

A estratégia foco mostrou-se sem importância, independentemente do porte da empresa, corroborando com o resultado da análise anterior para os dados agregados.

Claramente verifica-se que os três grupos apresentam uma estratégia stuck-in-the-middle, porém com características diferentes. As grandes empresas do polo indicam que tanto as opções de baixo custo como de diferenciação são extremamente importantes, as médias indicam o posicionamento no baixo custo como extremamente importantes e de diferenciação 

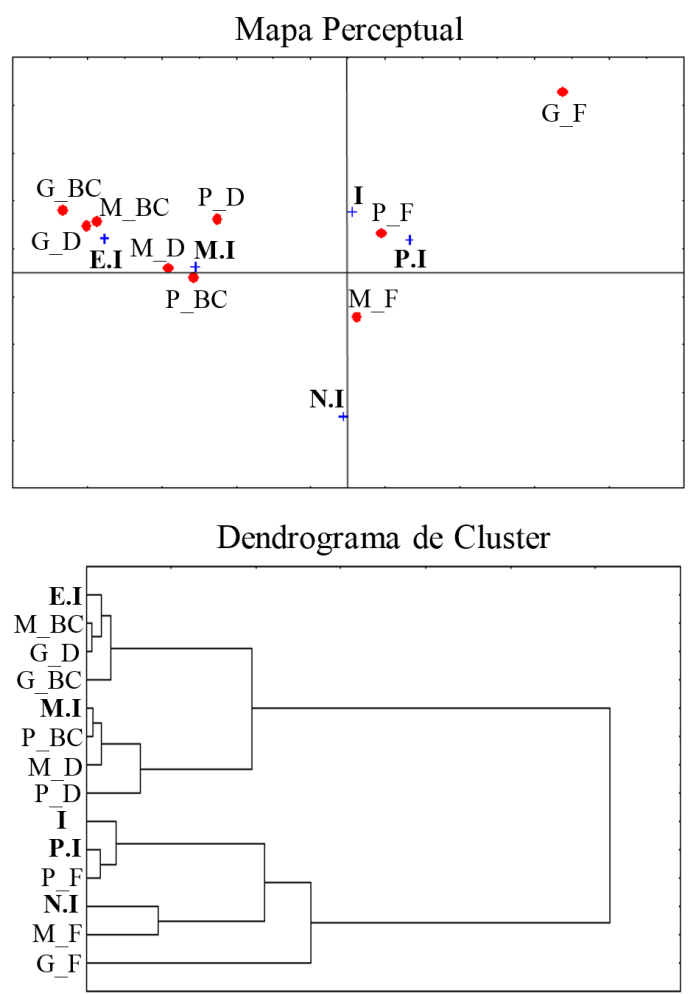

Figura 5. Indicativo da orientação estratégica para o porte das empresas.

Figure 5. Indicative of the strategic direction for the company size.

como muito importantes. As pequenas empresas consideram as duas opções estratégicas como muito importantes, com maior grau de importância para a tática de baixo custo.

Já, pelo que foi discutido anteriormente, verifica-se que as pequenas e médias empresas estão incorrendo no erro de visão de estratégia devendo as mesmas repensar suas propostas neste campo, sugerindo um fortalecimento da diferenciação como opção e até analisando as possibilidades de incrementar a tática de foco de foco, dado que essas empresas não possuem escala eficiente para serem lideres em custo baixo.

Já as grandes empresas, apesar de não seguirem uma estratégia pura, como preconizada por Porter (1980), mas criticada por outros autores, apresentam maior coerência. Seu tamanho permite propor um posicionamento de liderança em custo.

Porém, é importante considerar que as grandes empresas também apontaram a estratégia de diferenciação como extremamente importante, refletindo a perseguição de uma tática de diferenciação e baixo custo simultaneamente. Apesar de não recomendada por Porter (1980), já foi identificada por diversos autores em estudos semelhantes, empresas apresentaram resultados satisfatórios desenvolvendo esta estratégia híbrida.

As grandes empresas são quase na sua maioria exportadoras e têm como principal cliente os Estados Unidos seguido pela Europa. O mercado Norte-Americano, que também é o principal destino das exportações das empresas moveleiras chinesas, é o de móveis seriados, onde a concorrência é basicamente por preço.

Por outro lado, o mercado Europeu prioriza os móveis diferenciados, com maior valor agregado e de qualidade ressaltada. Este pode ser o posicionamento para pequenas e medias empresas, podendo justificar a perseguição da estratégia híbrida.

Provavelmente, a atuação em mercados distintos tem levado a busca por uma estratégia híbrida, se por um lado a diversificação de mercados pode possibilitar uma diminuição de risco como uma crise em um determinado mercado, por outro, impossibilita o desenvolvimento de uma posição única e mais eficiente que a concorrência.

\subsubsection{Estratégia por direcionamento da produção}

A Figura 6 permitiu identificar a importância atribuída para cada estratégia genérica pelas empresas com direcionamento ao mercado interno ou externo. Nesta análise, verifica-se de forma mais clara as opções estratégicas das firmas devido à opção de mercado de atuação.

As empresas orientadas ao mercado externo continuam apresentando uma estratégia híbrida, porém apresenta mais claramente a opção pelo posicionamento no baixo custo seguido pela diferenciação e, aqui se percebe que a tática de foco também tem uma importância para as firmas voltadas para as exportações.

Obviamente que esta é uma análise de um polo e, por consequência, podem existir firmas que estejam trabalhando em estratégia pura, ou muito próxima a isso. Porém novamente o erro estratégico aparece, visto que é um polo com pequenas e médias empresas com pouca diferenciação em produtos (a maioria são 

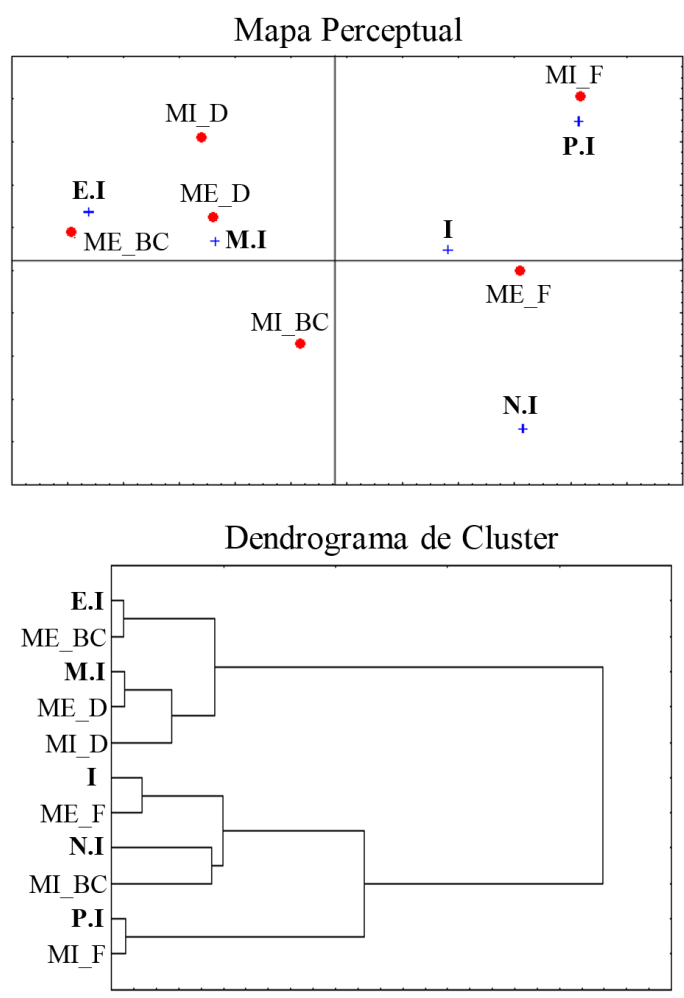

Figura 6. Indicativo da orientação estratégica conforme a orientação da produção.

Figure 6. Indicative of the strategic orientation according the orientation of production.

retilíneos) e mostrando a maior opção pra custo baixo, difícil de conseguir competir dentro das condições já descritas.

Novamente sugere, principalmente para as pequenas e médias empresas que atuam no mercado externo, o fortalecimento das estratégias de diferenciação e/ou foco, fugindo de segmentos de mercados externos que priorizam o preço baixo nas negociações.

Para isso, é necessária uma mudança de cultura empresarial que está voltada a considerar que a competitividade se dá fundamentalmente por preço baixo e para isso devem reduzir custos.

\section{CONCLUSÕES}

A análise dos dados agrupados nos permite concluir que os grupos estratégicos formados não apresentam claramente as estratégias genéricas puras de Porter (1980). Por outro lado, com a análise dos dados desagregados foi possível visualizar uma orientação estratégica mais clara dos grupos quando relacionados ao mercado que direcionam a produção e ao tamanho da empresa, uma vez que a essência da formulação de uma estratégia competitiva é relacionar uma companhia ao seu meio ambiente.

Pela análise dos dados desagregados, as grandes empresas perseguem a estratégia de baixo custo e diferenciação, apesar de não recomendado por Porter (1980). Além dos recursos, requisitos exigidos e mercados onde essas empresas competem, torna-se a mais recomendada à adoção de estratégia híbrida.

A falta de importância atribuída à estratégia de enfoque reflete a forma de negociação mais comum no polo, uma vez que, a negociação com os clientes se dá via mark-up e com projetos pré-definidos, o que leva o produtor a aceitar as especificações exigidas e não a buscar novos nichos de mercados com clientes dispostos a pagar mais por produtos que atendam suas necessidades específicas.

\section{STATUS DA SUBMISSÃO}

Recebido: 6 maio, 2013

Aceito: 25 jun., 2015

\section{AUTOR(ES) PARA CORRESPONDÊNCIA}

\section{Alexandre Nascimento de Almeida}

Faculdade Unb Planaltina - FUP, Universidade de Brasília - UnB, Área Universitária, 1, Vila Nossa Senhora de Fátima, CEP 73300-000, Brasília, DF, Brasil e-mail: alexalmeida@unb.br

\section{REFERÊNCIAS}

Banco Nacional de Desenvolvimento do Extremo Sul - BRDE. Análise da competitividade das principais aglomerações produtivas de móveis da região sul do Brasil. Florianópolis: BRDE; 2006. 233 p.

Coelho MH. Estratégias competitivas da indústria moveleira: um estudo de caso em empresas do polo moveleiro de São Bento do Sul (SC) [tese]. Curitiba: Setor de Ciências Agrárias, Universidade Federal do Paraná; 2003.

Denk A. Estudo setorial do cluster industrial moveleiro da região do Alto Vale do Rio Negro. São Bento do Sul: SINDUSMÓBIL; Rio Negrinho: SINDICOM; 2006.

Dess GG, Davis PSP. Generic strategies as determinants of strategic group membership and organizational 
performance. Academy of Management Journal 1984; 27(3): 467-488. http://dx.doi.org/10.2307/256040.

Gorini APF. A Indústria de móveis no Brasil. São Paulo: ABIMÓVEL; 2000.

Hair JF Jr, Anderson RE, Tatham RL, Black WC. Análise multivariada de dados. 5. ed. Porto Alegre: Bookman; 2005.593 p.

Hambrick DC. An empirical typology of mature industrialproducts environments. Academy of Management Review 1983a; 26(2): 213-230. http://dx.doi.org/10.2307/255971.

Hambrick DC. High profit strategies in mature capital goods industries: a contingency approach. Academy of Management Review 1983b; 26(4): 687-707. http://dx.doi. org/10.2307/255916.

Hoffman D, Franke G. Correspondence analysis: graphical representation of categorical data in marketing research. Journal of Marketing Research 1986; 23(3): 213-227. http:// dx.doi.org/10.2307/3151480.

Instituto Brasileiro Geográfico de Estatística - IBGE. Pesquisa Industrial Anual [online]. Rio de Janeiro: IBGE; 2014. [citado 2014 abr. 16]. Disponível em: www.ibge.gov.br

Levine DM, Berenson ML, Stephan D. Estatística: Teoria e Aplicações usando Microsoft Excel em Português. Rio de Janeiro: LTC; 2000.

Loper AA. Determinação da orientação estratégica do polo moveleiro do Alto Vale do Rio Negro-SC pela aplicação de métodos de análise multivariada [dissertação]. Curitiba: Setor de Ciências Agrárias, Universidade Federal do Paraná; 2007.

Martins G. Percepção dos empresários sul-brasileiros do setor de móveis em relação a ALCA [dissertação]. Curitiba: Setor de Ciências Agrárias, Universidade Federal do Paraná; 2003.

Miles RE, Snow CC, Meyer AD, Coleman HJ Jr. Organizational strategy structure and process. Academy of Management Review 1978; 3(3): 546-562. PMid:10238389.
Miller A, Dess GG. Assessing Porter's (1980) model in terms of its generalizability, accuracy and simplicity. Journal of Management Studies 1993; 30(4): 553-585. http://dx.doi.org/10.1111/j.1467-6486.1993.tb00316.x.

Mintzberg H. Generic strategies: toward a comprehensive framwork. In: Shrivastava P, editor. Advances in strategic management. Michigan: Emerald; 1988. vol. 5. p. 1-67.

Murray AI. A contingency view of Porter's: generic strategies. Academy of Management Review 1988; 13(3): 390-400. http://dx.doi.org/10.5465/AMR.1988.4306951.

Porter ME. Competitive advantage: creating and sustaining superior performance. New York: Free Press; 1980.

Porter ME. Estratégia competitiva: técnicas para análise de indústrias e da concorrência. 18. ed. Rio de Janeiro: Campus; 1991.

Silva JCGL. Análise da formulação de estratégias de marketing internacional de empresas brasileiras de papel e celulose [tese]. Piracicaba: Escola Superior de Agricultura "Luiz de Queiroz", Universidade de São Paulo; 1996.

Sistema de Análise das Informações de Comércio Exterior - AliceWeb [Internet]. Brasília: Ministério do Desenvolvimento, Indústria e Comércio Exterior; 2014. [citado em 2014 abr. 16]. Disponível em: http://aliceweb. desenvolvimento.gov.br

Universidade Estadual de Campinas - UNICAMP. Estudo da competitividade de cadeias integradas no Brasil: impactos das zonas de livre comércio. Campinas: UNICAMP; 2002. 212 p. Relatório técnico. Cadeia: Madeira e Móveis.

Vasques AG. A identificação da orientação estratégica da empresa florestal no Brasil: uma aplicação da teoria de Porter [tese]. Curitiba: Setor de Ciências Agrárias, Universidade Federal do Paraná; 2006.

Weyne GRS. Determinação do tamanho da amostra em pesquisas experimentais na área de saúde. Arquivos Médicos do ABC 2004; 29(2): 87-90. 